\title{
References
}

1 Camp PG, Ramirez-Venegas A, Sansores RH, et al. COPD phenotypes in biomass smoke- versus tobacco smokeexposed Mexican women. Eur Respir J 2014; 43: 725-734.

2 Agustí A. Phenotypes and disease characterization in chronic obstructive pulmonary disease. Toward the extinction of phenotypes? Ann Am Thorac Soc 2013; 10: Suppl., S125-S130.

3 Ramírez-Venegas A, Sansores RH, Pérez-Padilla R, et al. Survival of patients with chronic obstructive pulmonary disease due to biomass smoke and tobacco. Am J Respir Crit Care Med 2006; 173: 393-397.

4 González M, Páez S, Jaramillo C, et al. Enfermedad pulmonary obstructiva crónica (EPOC) por humo de leña en mujeres. Comparación con la EPOC por cigarillo [Chronic obstructive pulmonary disease (COPD) produced by woodsmoke in women]. Acta Med Colomb 2004; 29: 17-25.

5 González-García M, Maldonado D, Torres-Duque C, et al. Tomographic and functional differences between severe chronic obstructive pulmonary disease related to wood smoke and tobacco smoke. J Bras Pneumol 2013; 39: 147-154.

6 Moreira MAC, Barbosa MA, Queiroz MCCAM, et al. Pulmonary changes on HRCT scans in nonsmoking females with COPD due to wood smoke exposure. J Bras Pneumol 2013; 39: 155-163.

7 González-García M, Torres-Duque CA, Bustos A, et al. Bronchial hyperresponsiveness in women with chronic obstructive pulmonary disease related to wood smoke. Int J Chron Obstruct Pulmon Dis 2012; 7: 367-373.

\section{Exercise and cardiovascular benefit in subjects with COPD: the need for randomised trials}

\author{
To the Editor:
}

We read with interest the work on arterial stiffness in patients with chronic obstructive pulmonary disease (COPD) and the potential role of pulmonary rehabilitation by VANFLETEREN et al. [1] in the European Respiratory Journal. Arterial stiffness, as assessed by aortic pulse wave velocity (PWV), is an independent predictor of cardiovascular outcome and may improve risk stratification in selected patient groups [2]. Furthermore, there is now firm evidence that aortic stiffness is increased in patients with COPD [3, 4], even in those without coexistent diabetes mellitus or overt cardiovascular disease. Increases in arterial stiffness have a number of deleterious nonatherosclerotic consequences including renal, cardiac and further vascular damage.

In addition to age, aortic PWV is affected by structural and functional components as well as the distending pressure: mean arterial blood pressure (MAP). There is accumulating evidence of a role for chronic inflammation [5] in both the functional and structural elements, and interventional anti-inflammatory trials have suggested improved aortic stiffness in other inflammatory conditions. In patients with COPD, several studies have shown associations of aortic stiffness with systemic inflammatory mediators $[3,6]$ and one determined increased vascular wall inflammation using positron emission tomography/computed tomography fluorodeoxyglucose imaging [7]. Anti-inflammatories may be one way to reduce aortic stiffness in COPD but others also need to be explored.

Numerous therapeutic strategies have been employed to attenuate the increased aortic PWV across many conditions, including pharmacological, nutritional and lifestyle modification, such as optimising exercise. Indeed, interpretation of many trials has proved problematical as many of the interventions, including exercise, have produced significant reductions in MAP [8].

It is against this background that two studies in subjects with COPD have shown significant reductions in aortic PWV with exercise and/or pulmonary rehabilitation [9, 10]. As expected, there were significant reductions in MAP that would largely account for the more modest reduction in aortic stiffness that, in its own right, would confer beneficial cardiological status to subjects. It is therefore very unexpected that the recent study by VANFLETEREN et al. [1] failed to produce any decrease in MAP despite a major aerobic component to the training. This may be attributed to the ability of the participants to maintain sufficient exercise intensity or confounders such as medications or timing of assessments. Furthermore, failure to 
measure aortic PWV occurred in a large proportion of patients at baseline $(n=51,24 \%)$, which is not our or other groups' usual experience and may therefore have inadvertently generated bias.

There is a great deal of heterogeneity between the studies published to date in terms of type and duration of exercise intervention, the magnitude of improvements in the functional outcome measures, inclusion of those with or without established cardiovascular disease, and the arterial bed assessed (carotid-femoral versus carotid-brachial), all of which undoubtedly will have contributed to the conflicting results. In the past, a similar controversy regarding the benefits of exercise intervention after myocardial infarction was resolved by the use of well-designed randomised controlled trials, which should be considered before discarding the likely cardioprotective role of pulmonary rehabilitation and the strong public health message of exercise improving cardiorespiratory health.

0 $@$ ERSpublications

RCTs of \#pulmrehab or \#exercise in patients with \#COPD are required to establish potential cardioprotective role http://ow.ly/tROVc

Charlotte E. Bolton ${ }^{1}$, Nichola S. Gale ${ }^{2}$ and John R. Cockcroft ${ }^{2}$

${ }^{1}$ Nottingham Respiratory Research Unit, School of Medicine, University of Nottingham, Nottingham, and ${ }^{2}$ Wales Heart Research Institute, Cardiff University, Cardiff, UK.

Correspondence: Charlotte E. Bolton, Nottingham Respiratory Research Unit, The University of Nottingham, School of Medicine, Clinical Sciences Building, City Hospital NUH Trust Campus, Hucknall Road, Nottingham NG5 1PB, UK. E-mail: charlotte.bolton@nottingham.ac.uk

Received: Jan 132014 | Accepted: Jan 182014

Conflict of interest: Disclosures can be found alongside the online version of this article at www.erj.ersjournals.com

\section{References}

1 Vanfleteren LE, Spruit MA, Groenen MT, et al. Arterial stiffness in patients with COPD: the role of systemic inflammation and the effects of pulmonary rehabilitation. Eur Respir J 2014; 43: 1306-1315.

2 Ben-Shlomo Y, Spears M, Boustred C, et al. Aortic pulse wave velocity improves cardiovascular event prediction: an individual participant meta-analysis of prospective observational data from 17,635 subjects. J Am Coll Cardiol 2014; 63: 636-646.

3 Sabit R, Bolton CE, Edwards PH, et al. Arterial stiffness and osteoporosis in chronic obstructive pulmonary disease. Am J Respir Crit Care Med 2007; 175: 1259-1265.

4 Maclay JD, McAllister DA, Mills NL, et al. Vascular dysfunction in chronic obstructive pulmonary disease. Am J Respir Crit Care Med 2009; 180: 513-520.

5 Yasmin, McEniery CM, Wallace S, et al. C-reactive protein is associated with arterial stiffness in apparently healthy individuals. Arterioscler Thromb Vasc Biol 2004; 24: 969-974.

6 Patel AR, Kowlessar BS, Donaldson GC, et al. Cardiovascular risk, myocardial injury, and exacerbations of chronic obstructive pulmonary disease. Am J Respir Crit Care Med 2013; 188: 1091-1099.

7 Coulson JM, Rudd JH, Duckers JM, et al. Excessive aortic inflammation in chronic obstructive pulmonary disease: an ${ }^{18}$ F-FDG PET pilot study. J Nucl Med 2010; 51: 1357-1360.

8 Vogel T, Lepretre PM, Brechat PH, et al. Effect of a short-term intermittent exercise-training programme on the pulse wave velocity and arterial pressure: a prospective study among 71 healthy older subjects. Int J Clin Pract 2013; 67: 420-426.

9 Vivodtzev I, Minet C, Wuyam B, et al. Significant improvement in arterial stiffness after endurance training in patients with COPD. Chest 2010; 137: 585-592.

10 Gale NS, Duckers JM, Enright S, et al. Does pulmonary rehabilitation address cardiovascular risk factors in patients with COPD? BMC Pulm Med 2011; 11: 20.

Eur Respir J 2014; 44: 263-264 | DOI: 10.1183/09031936.00009714 | Copyright @ERS 2014

\section{From the authors:}

We thank C.E. Bolton and colleagues for their interest in our report about arterial stiffness in patients with chronic obstructive pulmonary disease (COPD) [1]. Our paper has two major findings: 1) aortic pulse wave velocity (PWV) in COPD is not related to systemic inflammation; and 2) aortic PWV does not respond to pulmonary rehabilitation [1]. According to C.E. Bolton and colleagues, these findings are unexpected as two previous papers did report small, but significant reductions in aortic PWV with exercise and/or pulmonary rehabilitation [2, 3]. However, VIVODTZEV et al. [2] used carotid-brachial pulse wave velocity as an outcome of arterial stiffness, which is known to be more susceptible to modification by exercise training than central (aortic) elastic arteries [4]. GALE et al. [3] did use aortic PWV as an outcome of arterial stiffness and used similar methodology to our study. While GALE et al. [3] suggested that a reduction in mean arterial pressure accounted for the reduction in aortic PWV following rehabilitation in their sample of 22 patients with 